\title{
The role of the North Atlantic Oscillation in European climate projections
}

\author{
Clara Deser $^{1}{ }^{\mathbb{D}} \cdot$ James W. Hurrell $^{1} \cdot$ Adam S. Phillips $^{1}$
}

Received: 14 July 2016 / Accepted: 16 December 2016 / Published online: 30 December 2016

(C) The Author(s) 2016. This article is published with open access at Springerlink.com

\begin{abstract}
This study highlights the expected range of projected winter air temperature and precipitation trends over the next 30-50 years due to unpredictable fluctuations of the North Atlantic Oscillation (NAO) superimposed upon forced anthropogenic climate change. The findings are based on a 40-member initial-condition ensemble of simulations covering the period 1920-2100 conducted with the Community Earth System Model version 1 (CESM1) at $1^{\circ}$ spatial resolution. The magnitude (and in some regions, even the sign) of the projected temperature and precipitation trends over Europe, Russia and parts of the Middle East vary considerably across the ensemble depending on the evolution of the NAO in each individual member. Thus, internal variability of the NAO imparts substantial uncertainty to future changes in regional climate over the coming decades. To validate the model results, we apply a simple scaling approach that relates the margin-of-error on a trend to the statistics of the interannual variability. In this way, we can obtain the expected range of projected climate trends using the interannual statistics of the observed NAO record in combination with the model's radiativelyforced response (given by the ensemble-mean of the 40 simulations). The results of this observationally-based estimate are similar to those obtained directly from the CESM ensemble, attesting to the fidelity of the model's
\end{abstract}

Electronic supplementary material The online version of this article (doi:10.1007/s00382-016-3502-z) contains supplementary material, which is available to authorized users.

Clara Deser

cdeser@ucar.edu

1 Climate and Global Dynamics Division, National Center for Atmospheric Research, P.O. Box 3000, Boulder, CO 80307, USA representation of the NAO and the utility of this approach. Finally, we note that the interannual statistics of the NAO and associated surface climate impacts are subject to uncertainty due to sampling fluctuations, even when based on a century of data.

Keywords North Atlantic Oscillation - Climate projections $\cdot$ Climate prediction $\cdot$ Climate variability

\section{Introduction}

The North Atlantic Oscillation (NAO), the dominant mode of atmospheric circulation variability over the North Atlantic/European sector, is a leading governor of wintertime climate fluctuations in Europe, the Mediterranean, parts of the Middle East and eastern North America over a wide range of time scales from intra-seasonal to multi-decadal (e.g., Hurrell 1995; Hurrell et al. 2003). The NAO's prominent upward trend from the 1950s to the 1990s caused large regional changes in air temperature, precipitation, wind and storminess, with accompanying impacts on marine and terrestrial ecosystems, and contributed to the accelerated rise in global mean surface temperature (e.g., Hurrell 1996; Ottersen et al. 2001; Thompson et al. 2000; Visbeck et al. 2003; Stenseth et al. 2003). As an intrinsic mode of variability of the large-scale atmospheric circulation, the NAO requires no external forcing for excitation (e.g., Hurrell and Deser 2009; Branstator and Selten 2009). Indeed, its time series is well characterized as a predominantly stochastic process with an e-folding time scale of 10-14 days (Feldstein 2000; Wunsch 1999; Deser et al. 2010). Thus, interannual and longer time scale fluctuations of the NAO need not have an external cause (Bracco et al. 2004; Hurrell et al. 2004; Deser and Phillips 2009). On the other hand, 
changes in surface boundary conditions such as sea surface temperature (SST) anomalies in the tropics (Hoerling et al. 2001, 2004; Bracco et al. 2004), winds in the stratosphere (Scaife et al. 2014; Kidston et al. 2015), and radiative changes associated with increasing GHG concentrations (Selten et al. 2004; Deser et al. 2012) may also influence the NAO. Although some predictive skill for the NAO may be obtained through knowledge of anomalous boundary conditions, it is limited to lead times of a year or two at best (Scaife et al. 2014; Dunstone et al. 2016).

European climate over the coming decades and centuries will continue to be influenced by the NAO. However, with increases in GHG concentrations due to the burning of fossil fuels, human-induced climate change will also play a role. The relative magnitudes of the climate impacts induced by the naturally-occurring NAO and by anthropogenic factors will depend on the time horizon (e.g., next few decades vs. end of the twenty-first century), time-scale (interannual vs. multi-decadal), and parameter (temperature vs. precipitation) of interest (e.g., Deser et al. 2012). Anthropogenic forcing may also alter the characteristics of the NAO itself. For example, some studies project a slight positive shift in the probability distribution of NAO phase and a small northeastward displacement of its centers-ofaction by the end of the twenty-first century (Ulbrich and Christoph 1999; Branstator and Selten 2009; Deser et al. 2012; Barnes and Polvani 2015).

The purpose of this study is to examine the impact of the NAO on projected changes in winter (December-March average) terrestrial surface air temperature (SAT) and precipitation (P) over the next $30-50$ years. We make use of a 40-member ensemble of climate change simulations under historical and RCP8.5 radiative forcing scenarios for the period 1920-2100 conducted with the Community Earth System Model Version 1 (CESM1; Hurrell et al. 2013). Each member of the CESM "Large Ensemble" (hereafter referred to as the CESM-LE) is subject to the same radiative forcing, but begins from a slightly different atmospheric state in 1920 (Kay et al. 2015). This infinitesimal perturbation to the initial atmospheric state is enough to cause the individual ensemble members to diverge over time. The resulting ensemble spread, due entirely to unpredictable internally-generated climate variability, yields a range of future climate projections (Deser et al. 2014). Here, we focus on the range of projected climate trends that results from the superposition of the GHG-forced climate change signal and intrinsic variability of the NAO.

To validate the model results, we compare the pattern and magnitude of NAO variability in the historical portion of the CESM-LE to observations. We also make use of the fact that the expected range of trends due to sampling fluctuations is related to the magnitude of the interannual variability for a Gaussian time series (Thompson et al. 2015).
This relationship allows us to estimate the impact of the unforced component of NAO variability on future climate trends purely from observations. This approach provides a hybrid assessment of the combined influence of anthropogenic climate change [determined from the ensemble-mean of the CESM-LE or from the multi-model Coupled Model Intercomparison Project phase 5 (CMIP5) archive (Taylor et al. 2012)] and observed NAO variability on climate over the coming decades. Finally, we assess the extent to which NAO variability changes with climate change, using the CESM-LE as our test bed.

The rest of the paper is structured as follows. Section 2 provides details of the CESM-LE simulations, observational data sets, and methodology. Results are given in Sect. 3 and summarized in Sect. 4. The main paper contains results for trends over the next 30 years (2016-2045), while the Supplemental Material shows results for trends over the next 50 years (2016-2065).

\section{Data and methods}

\subsection{The CESM1 large ensemble (CESM-LE) and accompanying control simulations}

We make use of the new 40-member ensemble of climate change simulations under historical and RCP8.5 radiative forcing scenarios for the period 1920-2100 conducted with CESM1. As mentioned above, each member begins from the identical state in 1920, except for a random perturbation on the order of round-off error $\left(10^{-14} \mathrm{~K}\right)$ to the atmospheric temperatures. The initial state in 1920 is obtained from the first member, which begins in 1850 after branching from a 400-year control run (Kay et al. 2015).

We also make use of two lengthy control simulations conducted with CESM1 under constant 1850 radiative conditions: a 2200-year control run using the fully-coupled configuration (hereafter termed the "coupled control run"), and a 2600-year control run using only the atmospheric model component coupled to the land model component from CESM1 with a specified repeating seasonal cycle of sea surface temperatures (SSTs) and sea ice conditions taken from the long-term climatology of the fully-coupled control run (hereafter termed the "atmospheric control run").

\subsection{The CMIP5 ensemble}

We also make use of simulations in the CMIP5 archive. We use all available models that conducted simulations for the period 2016-2065 under the RCP8.5 radiative forcing scenario. If more than one simulation exists for a given model, we use only the first one. We then average all 38 model 
simulations together to obtain the multi-model mean, which we interpret as the forced response to the RCP8.5 scenario.

\subsection{Observational datasets}

We make use of three observational data sets that provide monthly mean coverage over the Northern Hemisphere continents for the period 1920-2012. We obtain surface air temperature (SAT) from the GISS Surface Temperature Analysis (GISTEMP) on a $2^{\circ}$ latitude $\times 2^{\circ}$ longitude grid and smoothed with a $250-\mathrm{km}$ spatial filter (Hansen et al. 2010). Other SAT data sets such as the Climatic Research Unit Temperature, version 4, (CRUTEM4; Osborn and Jones 2014), and the Merged Land-Ocean Surface Temperature analysis (MLOST), version 3.5, (Vose et al. 2012) give similar results (not shown). We obtain precipitation (P) from the Global Precipitation Climatology Centre (GPCC) data set on a $2.5^{\circ}$ latitude $\times 2.5^{\circ}$ longitude grid (Becher et al. 2013). Finally, we obtain sea level pressure (SLP) from the Twentieth Century Reanalysis, version 2, (Compo et al. 2011) on a $2^{\circ}$ latitude $\times 2^{\circ}$ longitude grid.

\subsection{Methods}

For each observational dataset and the historical portion of each CESM-LE simulation, we compute monthly anomalies by subtracting the long-term (1920-2012) monthly means from the corresponding month of each year. Similarly, for the 2016-2045 (2016-2065) segment of each CESM-LE simulation, we compute monthly anomalies by subtracting the long-term monthly means based on 2016-2045 (2016-2065) from the corresponding month of each year. We then form 4-month winter (December-March; DJFM) averages from the monthly anomalies. Finally, we compute linear trends over the next 30 years (2016-2045) and next 50 years (2016-2065) using linear least-squares regression analysis.

We compute the leading empirical orthogonal function (EOF) of detrended DJFM SLP anomalies over the domain $\left[20-70^{\circ} \mathrm{N}\right.$ and $\left.90^{\circ} \mathrm{W}-40^{\circ} \mathrm{E}\right]$ following Hurrell and Deser (2009). This is done for observations using the historical period 1920-2012, and for the CESM-LE using the historical and future portions of the simulations. The corresponding principal component (PC) time series is then standardized, and all spatial patterns are produced by regressing detrended anomalies of SLP, SAT, and P at each grid box on the standardized PC. In the case of the CESM-LE, we also compute the leading EOF of DJFM SLP trends across the 40 ensemble members, similar to the approach in Deser et al. (2014). The corresponding PC record consists of 40 values, one for each ensemble member. The 40 SLP, SAT and P trend values at each grid box are regressed onto the standardized PC to produce the associated trend regression maps.

\section{Results}

\subsection{Contrasting future NAO trends}

Figure 1 illustrates the range of projected changes in winter (DJFM) SLP, SAT and P over the next 30 years (2016-2045) resulting from the superposition of natural variability and forced climate change as simulated by the CESM-LE. For this figure, we have picked two ensemble members, simulations 13 and 25, that show large-amplitude SLP trend patterns that resemble the negative and positive phase of the NAO, respectively. Following convention, a positive NAO state is defined when SLP over the northern (central) North Atlantic is below (above) normal, and vice versa (e.g., Hurrell 1995). The contrasting atmospheric circulation trends in the two simulations give rise to different SAT and $\mathrm{P}$ trends over the adjacent continents. In particular, simulation 13 shows cooling over parts of northern Europe and pronounced warming over Greenland, while simulation 25 features strong warming over northern Europe and cooling over Greenland. These regions of cooling and enhanced warming result from different patterns of horizontal temperature advection implied by the contrasting SLP trends. These different SAT trends occur despite the fact that both simulations were subject to the identical radiative forcing and were conducted with the same model, highlighting the role of internal atmospheric circulation variability in any single model run.

The difference in the $\mathrm{P}$ trends in the two simulations is even more striking, with $\mathrm{P}$ increases (decreases) over southern Europe in simulation 13 (25), and oppositesigned changes over northern Europe. Such P trends are consistent with the anomalous large-scale atmospheric circulation changes. From these two illustrative examples, it is clear that internal variability in the large-scale atmospheric circulation can have a large impact on the magnitude and sign of future climate trends over Europe. The full set of SLP, SAT and P trend maps based on 2016-2045 for each of the 40 CESM-LE members is shown in Figs. S1 and S2.

Trend maps for the 50-year period 2016-2065 for two contrasting members (\#19 and \#31) of the CESM-LE are shown in Fig. S3. Even over the next 50 years, the polarity of the NAO and associated P trends over Europe is uncertain. And although the SAT trends in both simulations are positive, their amplitudes can vary substantially depending on the internal variability. 

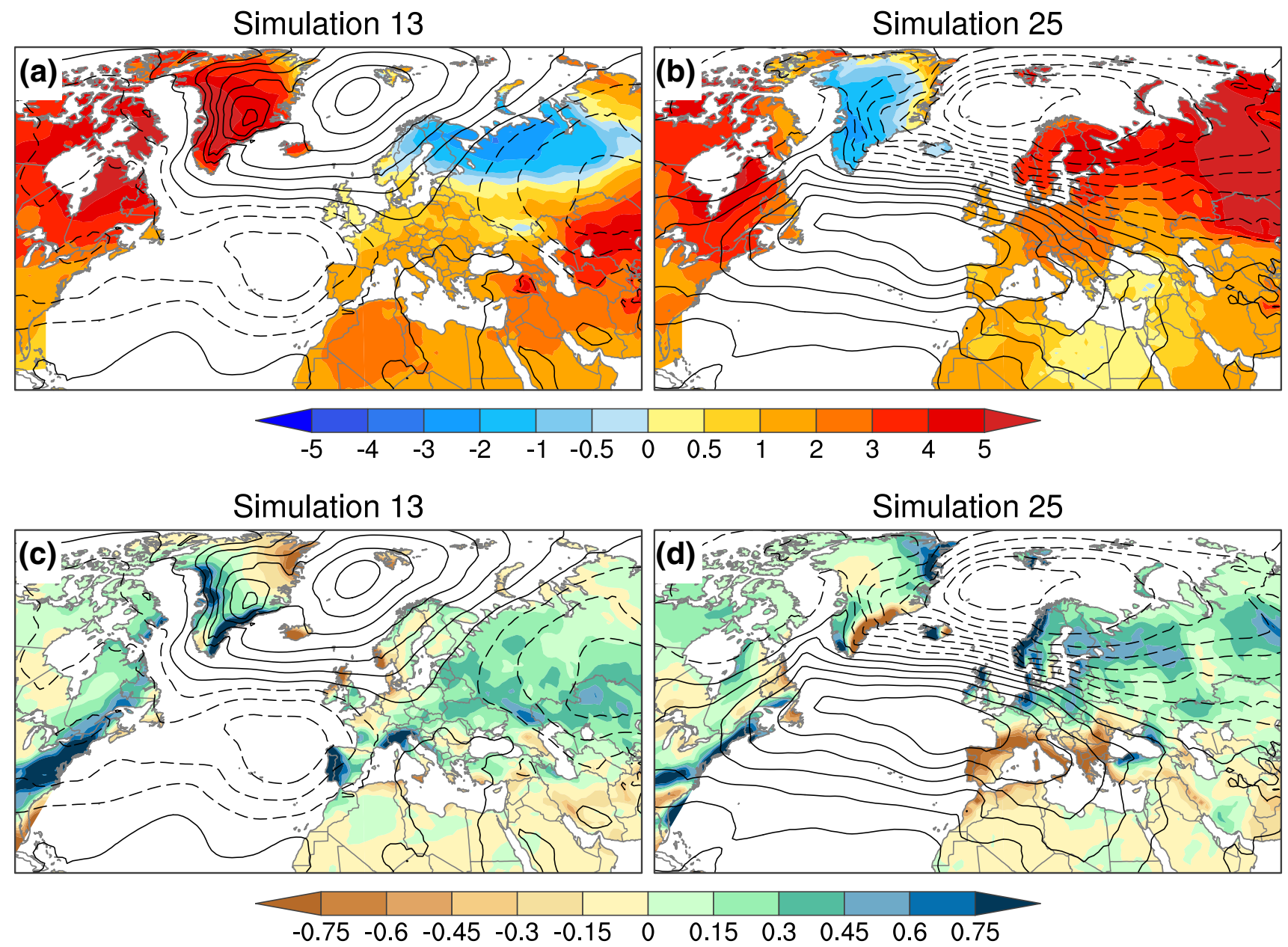

Fig. 1 Future 30-year trends (2016-2045) in winter (a, b) SAT $\left({ }^{\circ} \mathrm{C}\right.$ per 30 years; color shading) and $(\mathbf{c}, \mathbf{d})$ precipitation $\left(\mathrm{mm} \mathrm{day}^{-1}\right.$ per 30 years; color shading) from simulations 13 and 25 of the CESM1

\subsection{Generalizing the range of trends due to the NAO}

To generalize these results, we compute the leading EOF of winter SLP trends (2016-2045) across the 40 ensemble members of the CESM-LE as described in Sect. 2.4 (see also Deser et al. 2014). The leading mode explains $45 \%$ of the SLP trend variance and resembles the NAO, reinforcing the notion that the NAO is not only a dominant mode of variability on interannual time scales, but also on multidecadal time scales (Fig. 2a). We then regress the 40 SLP, SAT and P trend values at each grid box on the standardized SLP trend PC, and multiply these regression values by two. The resulting regression maps thus represent the trends associated with a two standard deviation departure $(\sigma)$ of the SLP trend PC.

This leading pattern of internal variability of 30-year trends can be compared to the forced component of 30-year trends, the latter obtained by averaging the trends from all 40 ensemble members (Fig. 2b). While
Large Ensemble, chosen for their contrasting SLP trends (contours; interval $=1 \mathrm{hPa}$ per 30 years with negative values dashed)

the forced SLP trend pattern projects onto the positive phase of the NAO, its amplitude is negligible compared to the internal variability of NAO trends. In particular, the forced SLP trend magnitudes are $<1 \mathrm{hPa}$ per 30 years everywhere except over Hudson's Bay and the Barents Sea where they reach 1-2 hPa per 30 years. [Hereafter, we shall omit the units "per 30 years" when citing trend values]. Similar forced SLP trends are obtained from the ensemble-mean of the CMIP5 multi-model archive (see below). The forced component of SAT trends shows warming everywhere, with magnitudes of $1-2{ }^{\circ} \mathrm{C}$ over Europe, northern Africa, Greenland and the eastern U.S., and slightly larger warming $\left(2-3^{\circ} \mathrm{C}\right)$ over Russia and Canada, with the largest SAT increases $\left(3-4{ }^{\circ} \mathrm{C}\right)$ surrounding Hudson's Bay (Fig. 2b). The forced component of $\mathrm{P}$ trends is generally small $(<0.15 \mathrm{~mm}$ day- 1 in absolute value), with decreases over northern Africa and southern Europe and increases elsewhere (Fig. 2f). 

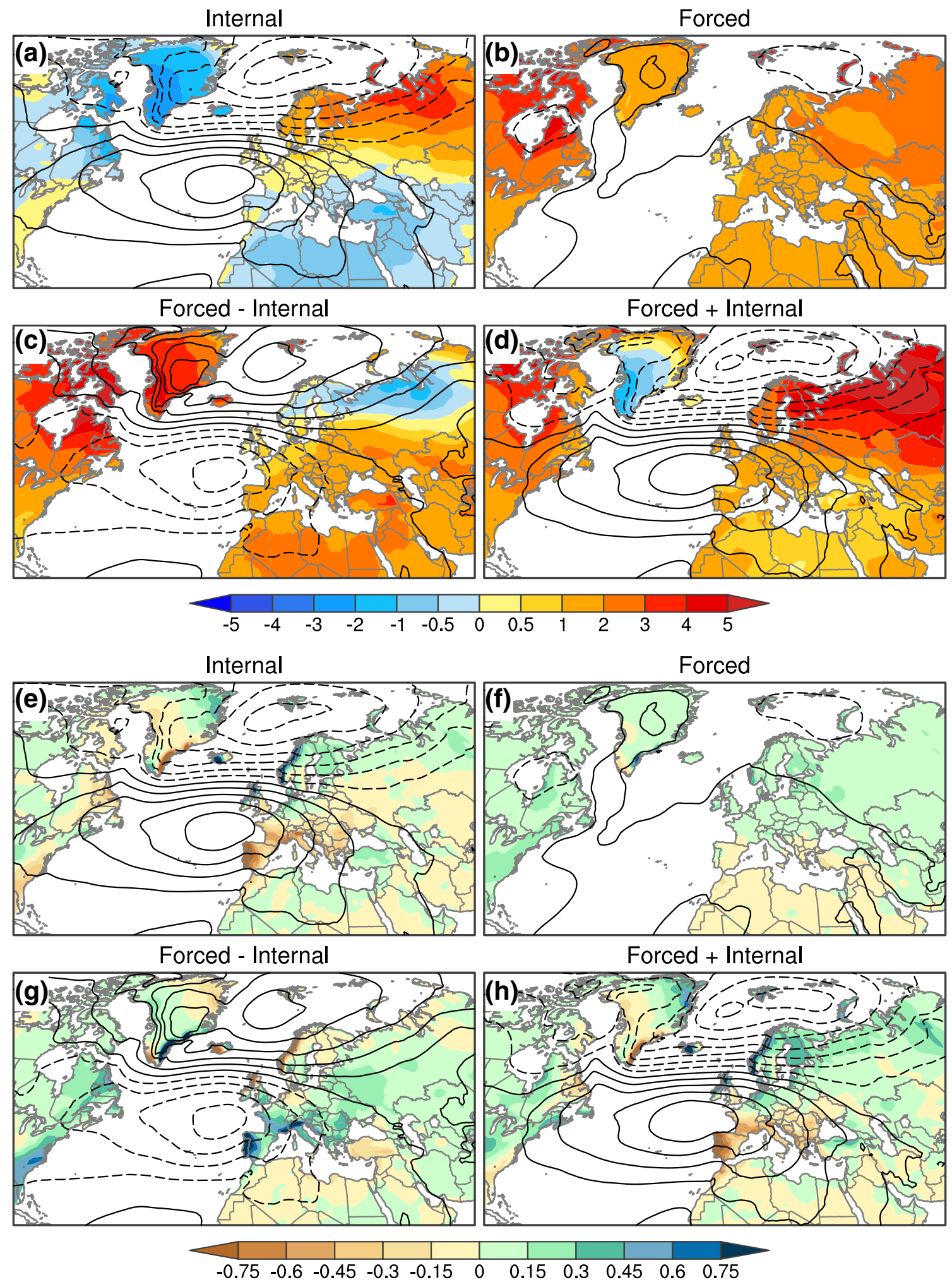

Fig. 2 Impact of the NAO on future 30-year climate trends (20162045). a Regressions of winter SLP and SAT trends upon the normalized leading PC of winter SLP trends in the CESM1 Large Ensemble, multiplied by two to correspond to a two standard deviation anomaly of the PC; $\mathbf{b}$ CESM1 ensemble-mean winter SLP and SAT trends; $\mathbf{c}$ $\mathrm{b}-\mathrm{a} ; \mathbf{d} \mathrm{b}+\mathrm{a}$. SAT in color shading $\left({ }^{\circ} \mathrm{C}\right.$ per 30 years $)$ and SLP in contours (interval $=1 \mathrm{hPa}$ per 30 years with negative values dashed). $\mathbf{e}-\mathbf{h}$ as in $\mathbf{a}-\mathbf{d}$ but for precipitation ( $\mathrm{mm}$ day $^{-1}$ per 30 years) in place of SAT 
Adding and subtracting the leading pattern of internal variability to/from the forced response yields the 5-95\% range of trend values due entirely to the superposition of the NAO and human-induced climate change (see Fig. 2c, $\mathrm{d}$ for SLP and SAT, and Fig. 2g, f for SLP and P). These NAO-induced "book-ends" of future climate trends are very similar to those depicted in the individual simulations shown earlier (Fig. 1), but instead of case studies, they are based on the dominant structure of internal atmospheric circulation variability across all 40 ensemble members superimposed upon the forced response. These future 30-year SAT and P trends exhibit substantially different patterns, polarities and magnitudes depending on the sign of the NAO trend. In particular, warming over northern Europe and Russia can vary from near-zero (or even slight cooling) to more than $4{ }^{\circ} \mathrm{C}$, and over northern Africa and parts of the Middle East from $<1^{\circ} \mathrm{C}$ to $>2{ }^{\circ} \mathrm{C}$, depending on whether the NAO trend is $+2 \sigma$ or $-2 \sigma$ (Fig. 2 c, d). Even more striking, the out-of-phase relationship between $\mathrm{P}$ trends over northern and southern Europe associated with the NAO (Fig. 2e) remains evident over the next 30 years despite human-induced climate change. That is, the sign of $\mathrm{P}$ trends in these locations is dictated by the polarity of the $2 \sigma$ NAO trend (Fig. $2 \mathrm{~g}, \mathrm{~h}$ ).

The 5-95\% range of NAO-induced climate trends over the next 50 years (2016-2065) is shown in Fig. S4. In analogy with the results based on 30-year trends, the leading EOF of 50-year SLP trends resembles the NAO in spatial structure, and its amplitude is much larger than the forced component of SLP trends. As a result, SLP trends over the next 50-years may display a positive or negative phase of the NAO. These opposing circulation trends impact the magnitude of future warming, but do not change its sign (Fig. S4 c,d). However, they do alter the sign of P trends over southern Europe, and modulate the amplitude of future P increases over northern Europe and eastern North America (Fig. S4 g,h). These NAO-induced "book-ends" of climate trends over the next 50 years are very similar to those depicted in the two individual simulations shown in Fig. S3.

\subsection{Validating the model's NAO}

How well does CESM1 depict the NAO and associated surface climate impacts? Clearly, the observational record is too short to validate the trend characteristics of the model's NAO, but at least its interannual aspects can be assessed. Figure 3 compares the leading EOF of interannual winter SLP variability based on detrended data during 1920-2012 from observations (20CR) and the CESM-LE (note that the historical portion of the CESM-LE is used to match observations). For the model, we have computed the EOF for each ensemble member individually, and then averaged the
40 corresponding regression patterns based on the standardized PC time series to obtain robust ensemble-mean statistics. However, nearly identical results are obtained by applying EOF analysis to the concatenated set of detrended SLP anomalies from the 40 simulations (not shown). The observed interannual EOF accounts for $47 \%$ of the variance of detrended SLP anomalies during 1920-2012, and depicts the NAO with one center-of-action located between Greenland and Scandinavia, and the other of opposite polarity centered between the Azores and Spain (maximum values of approximately 4 and $3 \mathrm{hPa}$, respectively; Fig. 3a). The model's ensemble-mean EOF accounts for $43 \%$ of the variance on average across the 40 ensemble members, and is largely similar to observations although the centers-ofaction extend slightly farther east and the southern lobe is weaker (maximum amplitude of approximately $2 \mathrm{hPa}$ compared to $3 \mathrm{hPa}$ in observations; Fig. 3c). Note that although the NAO is the single most dominant mode in both observations and the CESM-LE, other patterns of North Atlantic circulation variability account for a little more than half of the total SLP variance.

The leading SLP EOF shows some variation in pattern and amplitude across the individual ensemble members, even though the statistics are based on such a long period of record (1920-2012). For example, simulation 14 shows magnitudes that are nearly identical to observations (Fig. 3b), while simulation 25 shows a stronger northern center-of-action (maximum amplitude around $5 \mathrm{hPa}$ ) and a weaker southern center (maximum amplitude of approximately $1.5 \mathrm{hPa}$; Fig. 3d). In addition, the percent variance explained by the leading EOF varies across the ensemble members, ranging from 32 to $49 \%$ (Fig. S5). Thus, the characteristics of the interannual NAO may not be precisely known with "only" 93 years of data, at least according to the CESM-LE. As a corollary, the observed NAO characteristics may also be subject to some uncertainty, and thus any individual simulation need not match observations exactly. However, for the model to be realistic, its range of NAO patterns and amplitudes must span the one "realization" from nature. By these measures, the CESM-LE produces a credible NAO, given the length of the observational record available for assessment. The temporal characteristics of the model's NAO will be considered below. The SAT and P anomalies associated with the leading interannual SLP EOF are also well simulated in the CESM-LE (Fig. 3). In particular, a positive NAO is associated with positive SAT anomalies over Europe, Russia and the eastern U.S., and negative SAT anomalies over northern Africa, the Middle East, eastern Canada and Greenland in both observations (Fig. 3a) and the ensemble-mean of the model simulations (Fig. 3c). In addition to the realistic spatial pattern of SAT anomalies, the simulated amplitudes are also in line with observations. However, as expected, the 

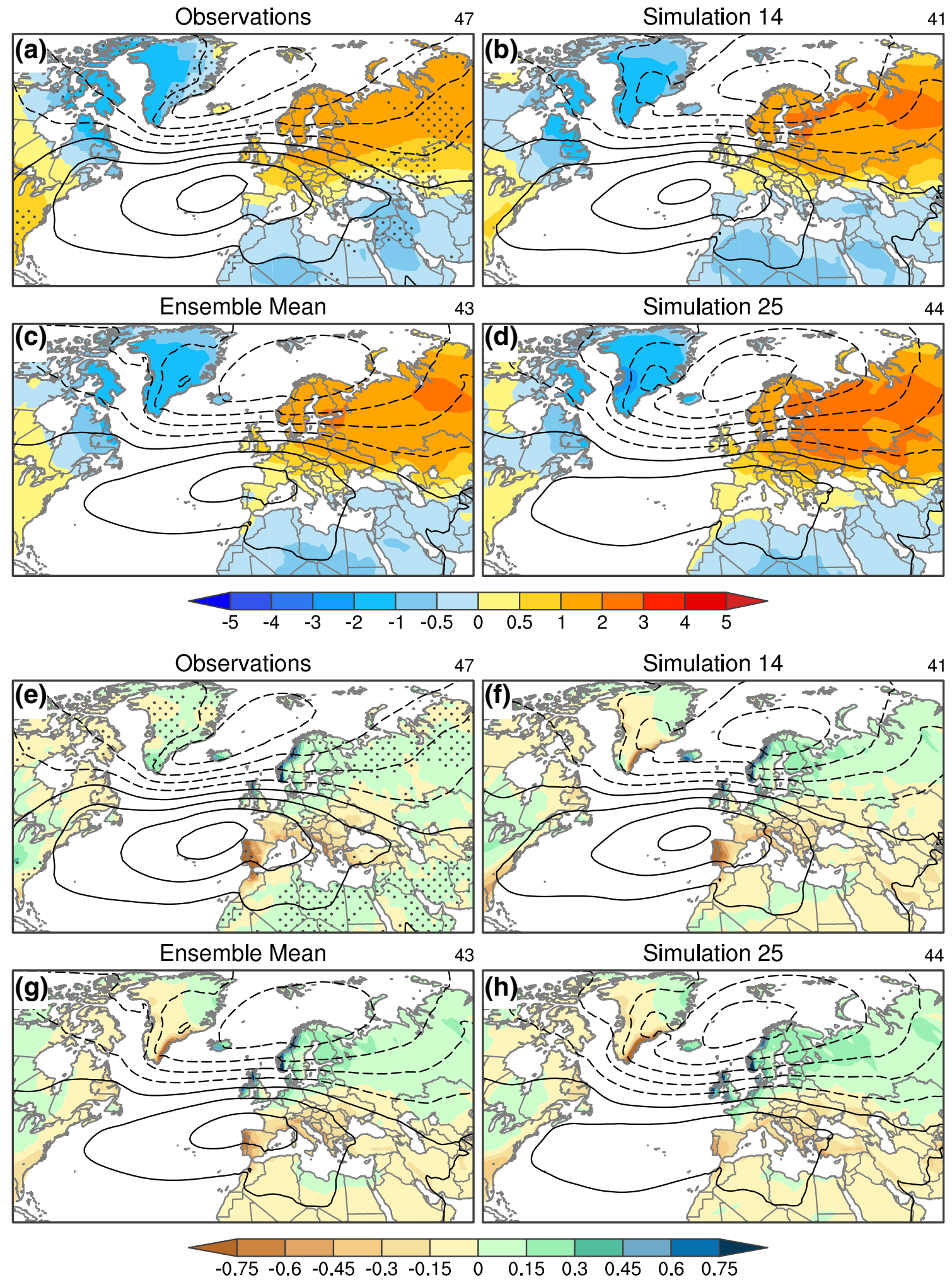

Fig. 3 Interannual NAO and associated SAT and precipitation anomalies. All panels show regressions upon the normalized leading PC of winter SLP anomalies based on detrended data during 1920-2012. SLP (contours; interval $=1 \mathrm{hPa}$ with negative values dashed) and SAT (color shading; ${ }^{\circ} \mathrm{C}$ ) from: a observations; b CESM1 simulation 14; c CESM1 ensemble mean; d CESM1 simulation 25. Stippled areas in panel (a) indicate where the observed SAT regression value lies outside the 40 values simulated by the CESM1 Large Ensemble. Panels $\mathbf{e}-\mathbf{h}$ as in $\mathbf{a}-\mathbf{d}$ but for precipitation $\left(\mathrm{mm} \mathrm{day}^{-1}\right)$ in place of SAT. Percent variance explained by the NAO PC indicated at the upper right of each panel 
magnitudes and spatial pattern of the SAT anomalies may vary across the individual ensemble members, consistent with the variation in the SLP anomalies. For example, simulation 25 shows larger SAT anomalies over central Europe (maximum values around $2-3{ }^{\circ} \mathrm{C}$ ) compared to observations (maximum values around $1-2^{\circ} \mathrm{C}$; Fig. $3 \mathrm{~d}$ ). However, the observed SAT anomalies lie within the range of values simulated across the 40 ensemble members of the CESMLE at nearly all locations, as indicated by the lack of stippling in Fig. 3a. Exceptions occur over portions of the Middle East, central Russia and the southeastern United States.

The model's ensemble-mean $\mathrm{P}$ anomalies exhibit a realistic dipole pattern, with the largest positive values (in excess of $0.75 \mathrm{~mm} \mathrm{day}^{-1}$ ) over northern Europe, especially the west coast of Great Britain and Scandinavia, and largest negative values of comparable amplitude over southern Europe, particularly Portugal, Spain, and other countries bordering the Mediterranean Sea (compare Fig. 3e, g). However, as with SAT, the magnitude of the P anomalies varies across the ensemble. For example, simulation 25 depicts smaller precipitation reductions over the Mediterranean region compared to simulation 14 , consistent with the weaker SLP amplitude over the southern center-ofaction (Fig. 3f, h). In addition to magnitude variations, the details of the spatial pattern of $\mathrm{P}$ anomalies can differ from one ensemble member to another: for example, France and Great Britain show negative $\mathrm{P}$ anomalies in simulation 14 and positive $\mathrm{P}$ anomalies in simulation 25. These variations in the position of the nodal line and amplitude of the $\mathrm{P}$ anomaly dipole associated with the NAO, which are due entirely to sampling fluctuations even with 93 years of record, has implications for paleo-climate reconstructions (Cook 2003).

The observed $\mathrm{P}$ regression values in areas most strongly affected by the NAO, which includes all of western and Eastern Europe and most of eastern North America, lie within the spread of the 40 values simulated across the CESM-LE (Fig. 3e). The observed P anomalies over northern Russia and much of North Africa lie outside of the model spread.

The $5-95 \%$ range of simulated NAO regression values across the 40 ensemble members is summarized in Fig. 4. This range is constructed by computing the standard deviation $(\sigma)$ of the 40 regression values at each grid box for
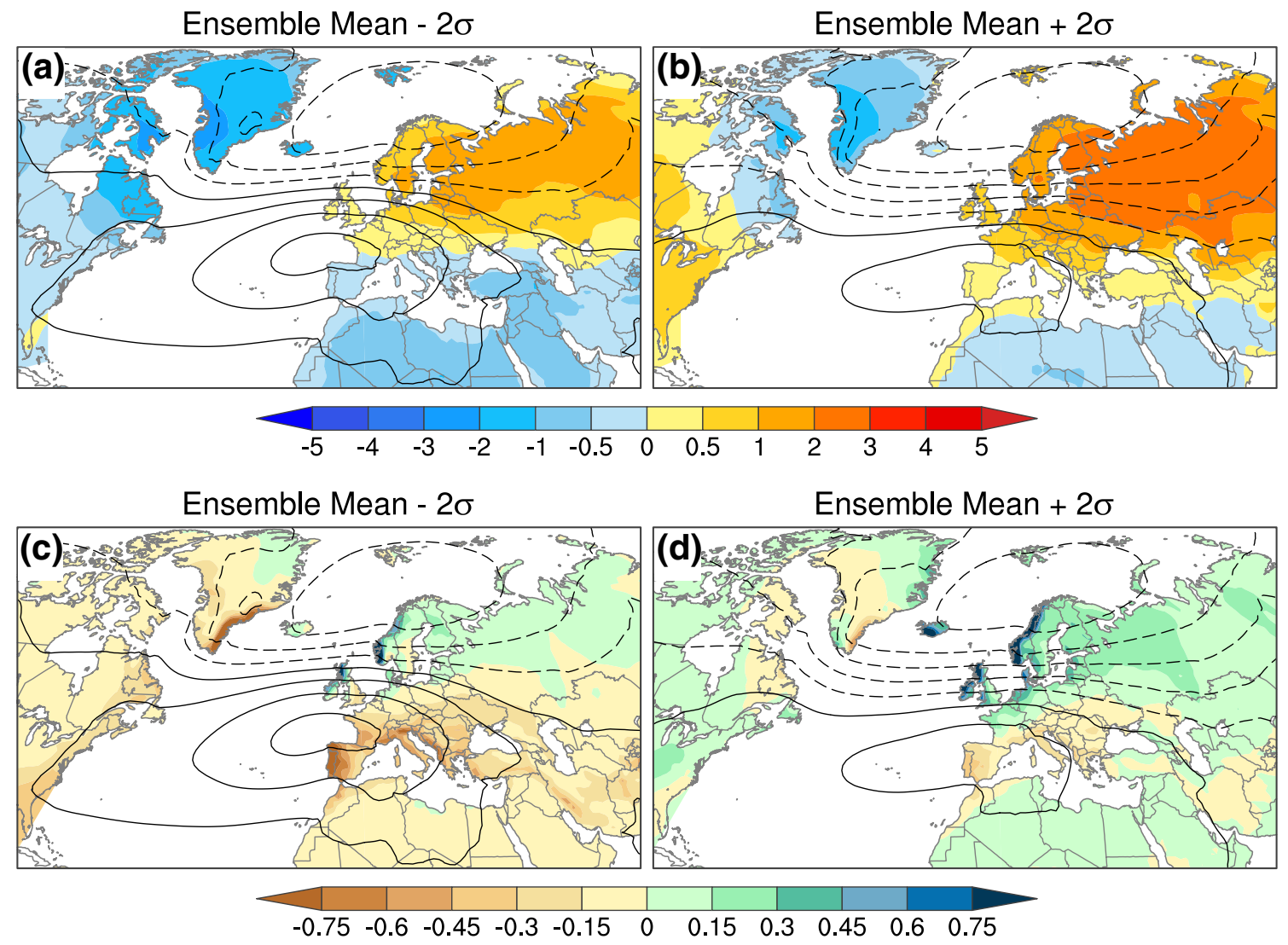

Fig. 4 The 5-95\% range of interannual NAO regression values across the 40 members of the CESM1 Large Ensemble based on detrended data during 1920-2012. (a) and (b) show SLP (contours; interval $=1 \mathrm{hPa}$ with negative values dashed) and SAT (color shad- ing; $\left.{ }^{\circ} \mathrm{C}\right)$ regressions associated with a -2 and +2 standard deviation departure of the NAO, respectively. $\mathbf{c}, \mathbf{d}$ as in $\mathbf{a}$ and $\mathbf{b}$ but for precipitation $\left(\mathrm{mm} \mathrm{day}^{-1}\right)$ in place of SAT. See text for details 
each variable (SLP, SAT and P) based on detrended data during 1920-2012, and subtracting/adding these values (multiplied by two) from/to the ensemble mean regression value. Note that these regression maps are intended to convey the $5-95 \%$ range of uncertainty in the simulated interannual NAO regression values arising from sampling fluctuations, and should not be interpreted as patterns occurring in any individual simulation. There is a large range of uncertainty in the SAT regression values over northern Europe and Russia $\left(1-3{ }^{\circ} \mathrm{C}\right)$, and in the P regression values over western Europe $\left(0.15-0.75 \mathrm{~mm} \mathrm{day}^{-1}\right)$. This range is associated with uncertainty in the overlying large-scale SLP regression pattern. In particular, a stronger southern center-of-action of the NAO (i.e., a stronger high pressure anomaly) and a northward shift of the SLP dipole nodal line is associated with greater precipitation deficits over southern and central Europe; and a southward shift of the nodal line accompanied by stronger anomalous westerly flow across northern Europe and Russia favors enhanced precipitation and warming in these regions (Fig. 4). This range of uncertainty on the simulated NAO and its climate impacts cautions against over-interpreting results based on "only" 93-years of data, be it from a model run or from nature.

Up to now, we have focused on the spatial characteristics of climate anomalies associated with historical NAO variability. It is also useful to examine the temporal characteristics of the NAO. As mentioned in the Introduction, the observed NAO exhibits prominent low-frequency variability on time scales of decades and longer. Does the CESMLE show similar low-frequency fluctuations, and to what extent are these forced? The NAO time series from observations and each of the first 30 members of the CESM-LE over the period 1920-2012 are displayed in Fig. 5 (only the first 30 members are shown to save space). A 10-year lowpass filter has been applied to each record to highlight decadal and longer time scales. While the individual ensemble members exhibit realistic amplitudes of low-frequency variability, this variability is almost entirely internally generated as seen by the comparatively small magnitude of the forced response (given by the 40-member ensemble-mean time series shown in the lower right panel of Fig. 5). Given that the model's low-frequency NAO variability is almost entirely internally-generated, and if the same is true for observations, then the chronologies of the simulated and observed NAO time series need not match. Indeed, the NAO shows a wide variety of temporal sequences across the 30 members of the CESM-LE, with ensemble member 5 lining up with the observed record just by chance (Fig. 5).

It is important to note that we have focused only on the low-pass filtered portion of the NAO time series. The full NAO record exhibits energetic inter-annual fluctuations (not shown), and consequently there is very little autocorrelation in any of the simulated time series, consistent with observations (Fig. S5b). The 1-year lag autocorrelation of the detrended NAO timeseries during 1920-2012 ranges from -0.28 to +0.16 across the 40 members of the CESM-LE, with an average of -0.05 (Fig. S5b). The observed autocorrelation ( +0.17 based on detrended data) lies just outside the high end of this range, but not significantly so. Note that the range of simulated autocorrelation values is entirely due to sampling fluctuations associated with a short record: none are significantly different from zero.

\subsection{Using the statistics of interannual NAO variability to infer the range of NAO trends}

\subsubsection{Application to CESM1}

For a Gaussian time series, the margin of error on a trend of length $N_{t}$ estimated by linear least-squares regression is a function of the magnitude of the interannual variability (given by the standard deviation $\sigma$ ), the lag-one autocorrelation and the trend length (Thompson et al. 2015). For the case of zero autocorrelation, the two-tailed $95 \%$ margin of error on a 30 -year (50-year) trend is $\sigma$ multiplied by 1.27 (0.98). The dependence of these values on the lag-one autocorrelation is given in Figure 2 of Thompson et al. (2015).

To see how well this relationship holds for the model's NAO in the absence of climate change, we make use of the 2200-year coupled (CESM1) pre-industrial control simulation described in Sect. 2.1. Specifically, we compute the leading EOF of detrended DJFM SLP anomalies over the entire length of the run (e.g., the "interannual" EOF), and also the leading EOF of 30-year trends formed from sequential 30-year segments of the run, overlapping by 15 years to increase the sample size, for a total of 146 trend samples. The corresponding PC records are then standardized and used to produce the SLP, SAT and P regression maps. Finally, we multiply the interannual regression maps by 1.27 , the appropriate value for the $95 \%$ margin of error on a 30-year trend given a 1-year lag autocorrelation of the PC timeseries of 0.01 . The resulting scaled-interannual and trend SLP regression maps closely resemble one another in both pattern and magnitude (Fig. 6), indicating that in the CESM control simulation the margin-of-error on a 30-year trend in the NAO can be well estimated from the statistics of the interannual variability of the NAO. The corresponding scaled-interannual and trend versions of the SAT and $\mathrm{P}$ regression maps are also very similar to one another (Fig. 6). The slight overestimate of the scaled-interannual SAT values over Russia and P values over Western Europe compared to their trend counterparts is consistent with the locally stronger gradients in the SLP field, which drive these surface climate impacts. 
Low-Pass NAO Timeseries (DJFM)

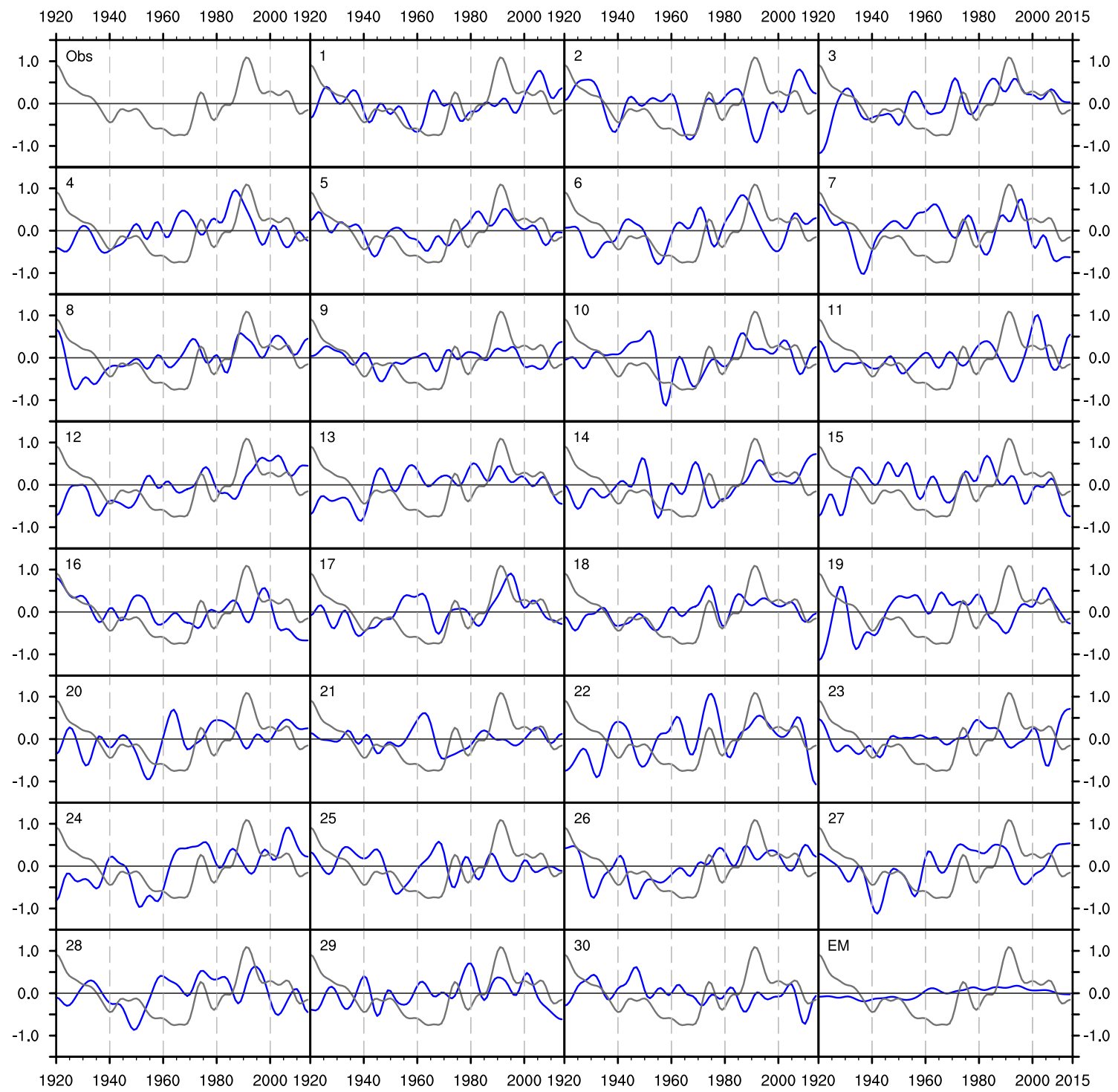

Fig. 5 Low-pass filtered NAO time series from each of the first 30 members of the CESM1 Large Ensemble (blue curves; numbers in upper left of each panel denote the ensemble member number) and from observations (gray curve in upper left panel, and repeated in

Repeating this exercise on the 2600-year atmospheric control simulation produces nearly identical results to the coupled control run (Fig. S6), indicating that the NAO and its terrestrial climate impacts are primarily a result of intrinsic atmospheric dynamics: i.e., this mode does not rely on air-sea interaction for its existence or dominant characteristics. Whether the slight differences in SLP amplitudes between the coupled and atmospheric control simulations can be attributed to ocean coupling (either local or remote) or to sampling fluctuations remains to be assessed. each subsequent panel) during the period 1920-2012. The lower right panel labeled "EM" shows the 40-member ensemble-mean NAO time series (blue), indicative of the forced response in CESM1. The vertical axes are identical for each panel

Having shown that the scaling method works well in the CESM control runs, we next ask: how well can the marginof-error on future trends in the NAO be inferred from the statistics of present-day interannual NAO variability? If they can be inferred to a reasonable degree, then one can use the observed characteristics of interannual NAO variability to estimate the error on future NAO trends, rather than relying solely on the model. We address this question using the CESM-LE as a test bed.

Figure 7 compares the scaled-interannual regressions based on the historical period (1920-2014) with the 

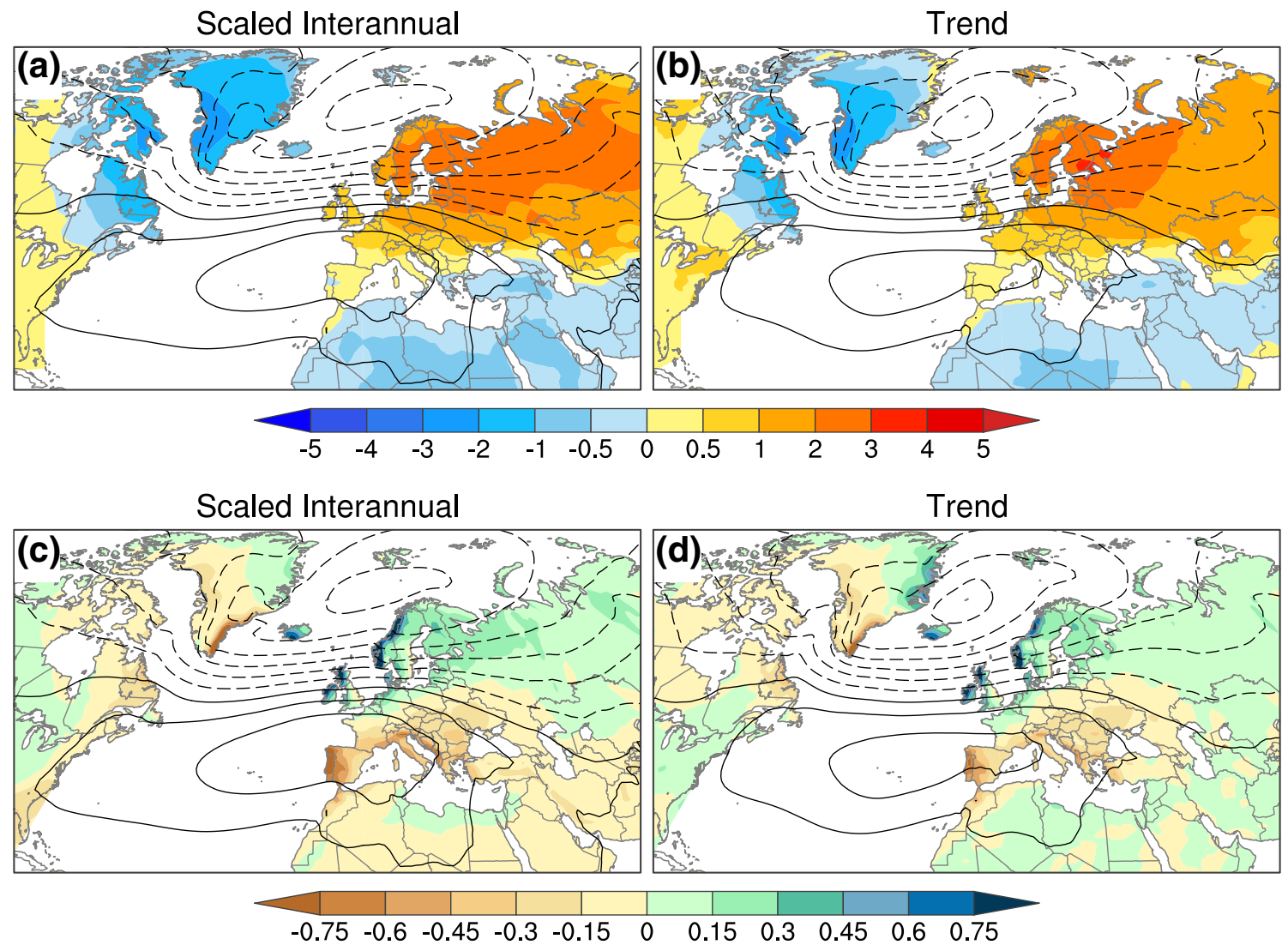

Fig. 6 Comparison between the NAO and associated climate impacts in the 2200-year CESM1 control integration computed from interannual data (scaled as described in the text) and from 30-year trends. a Scaled-interannual regressions of winter SLP (contours) and SAT (color shading) anomalies upon the normalized leading PC of winter SLP anomalies; b SLP and SAT trend regressions upon the normal-

regressions based on future (2016-2045) trends. Here, we have applied the interannual scaling factor appropriate to each individual ensemble member (autocorrelation values shown in Fig. S5b) and then averaged the resulting 40 scaled-interannual regression maps to produce the ensemble-mean results shown in Fig. 7a, c. Nearly identical results are obtained using the scaling factor appropriate for the average 1-year lag autocorrelation across the ensemble $(-0.05)$ to each member, or the scaling factor appropriate for zero autocorrelation to each member (not shown). It is worth noting that the average interannual characteristics of the model's NAO and associated SAT and P impacts do not change appreciably between the pre-industrial period (as given by the coupled control simulation: recall Fig. 6a, c) and the historical (Fig. 5a, c) or future (2016-2045: Figs. S7a and c) segments of the CESM-LE. That is, the dominant mode of winter atmospheric circulation variability in the Atlantic/European sector in the CESM is largely unaffected by climate change occurring between 1850 and 2045. ized leading PC of winter SLP trends; $\mathbf{c}$ As in (a) but for precipitation in place of SAT; $\mathbf{d}$ As in (b) but for precipitation in place of SAT. SAT in units of ${ }^{\circ} \mathrm{C}$ per 30 years, precipitation in units of $\mathrm{mm}^{\mathrm{day}}{ }^{-1}$ per 30 years, and SLP contour interval of $1 \mathrm{hPa}$ per 30 years with negative values dashed

It is evident from Fig. 7 that the model's scaled-interannual regressions based on the historical period and the trend regressions based on the next 30 years are largely similar in structure, with some regional differences in amplitude. In particular, the SLP trend regressions show greater magnitudes over the central North Atlantic and a slight northward shift in the nodal line compared to their scaled-interannual counterparts. These differences in SLP are reflected in the SAT and P fields, with more pronounced cooling and drying over southern Europe in the trends compared to the scaled-interannual fields. In addition, Western Russia exhibits greater warming in the trend regressions than the scaled-interannual regressions, with maximum values around $3-4{ }^{\circ} \mathrm{C}$ compared to $2-3{ }^{\circ} \mathrm{C}$. These regional differences in amplitude notwithstanding, the large-scale features of the SLP, SAT and P regression maps show a strong degree of resemblance between the version based on historical scaled-interannual statistics and that based on future 30-year trends. The comparison between the historical scaled-interannual and future trend regression maps is 
Scaled Interannual

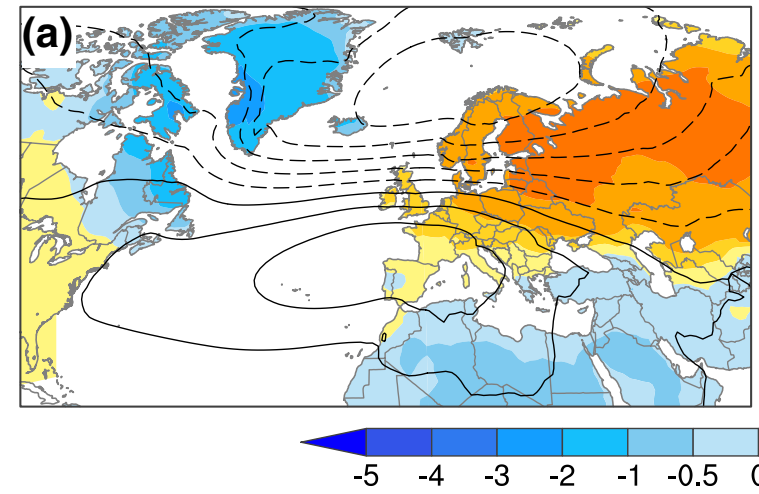

Scaled Interannual
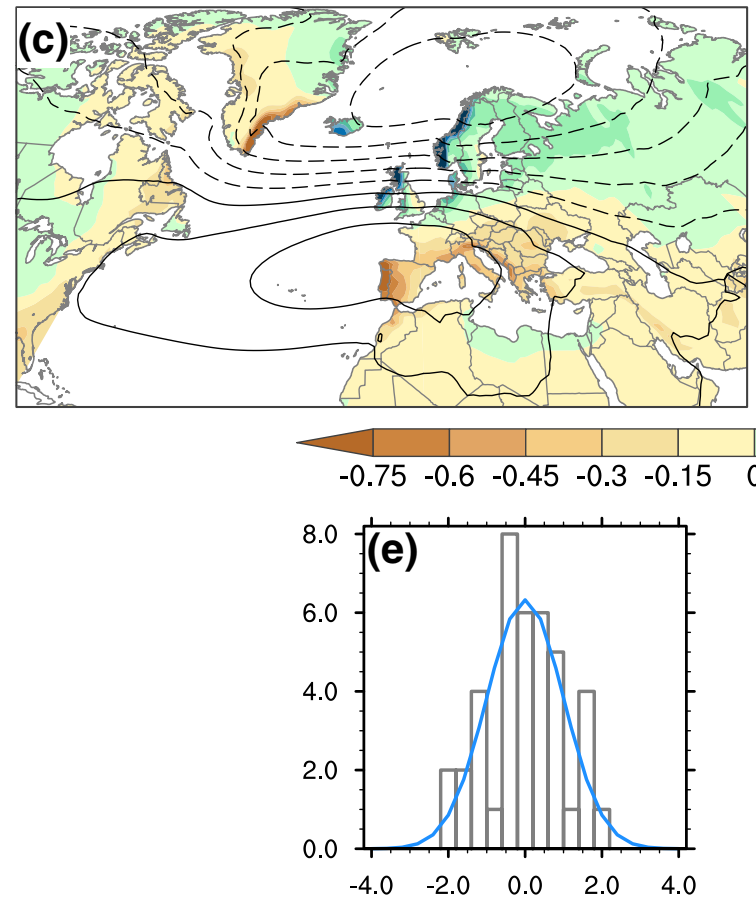

Fig. 7 As in Fig. 6 but using the CESM1 Large Ensemble. a Ensemble-mean of scaled-interannual regressions of winter SLP (contours) and SAT (color shading) anomalies upon the normalized leading PC of winter SLP anomalies during 1920-2012; b SLP and SAT trend regressions upon the normalized leading PC of winter SLP 30-year trends based on 2016-2045; $\mathbf{c}$ as in (a) but for precipitation in place of SAT; $\mathbf{d}$ as in (b) but for precipitation in place of SAT. SAT in units

even closer when considering trends over the next 40 years (Fig. S8) and the next 50 years (Fig. S9).

The reasons for the regional differences in historical scaled-interannual and future 30-year trend regressions are unclear, since as noted above the model's interannual NAO variability does not appear to be affected by climate change between 1850 and 2045. Sampling variability may account for some, but not all, of the regional SLP differences, as evidenced by the range of results obtained from random sub-samples of the CESM-LE members (not shown). The

\section{Trend}

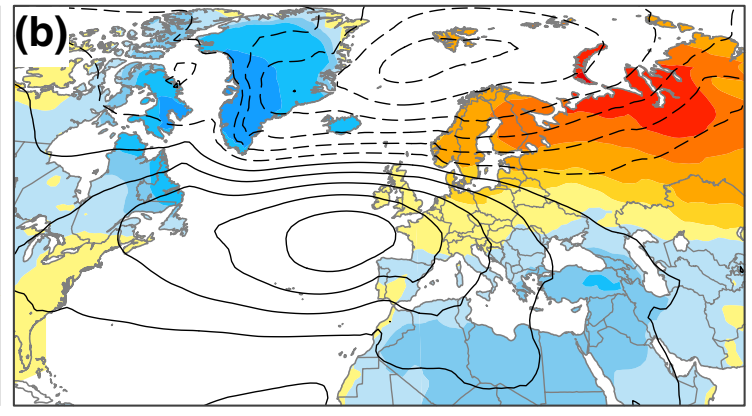

Trend
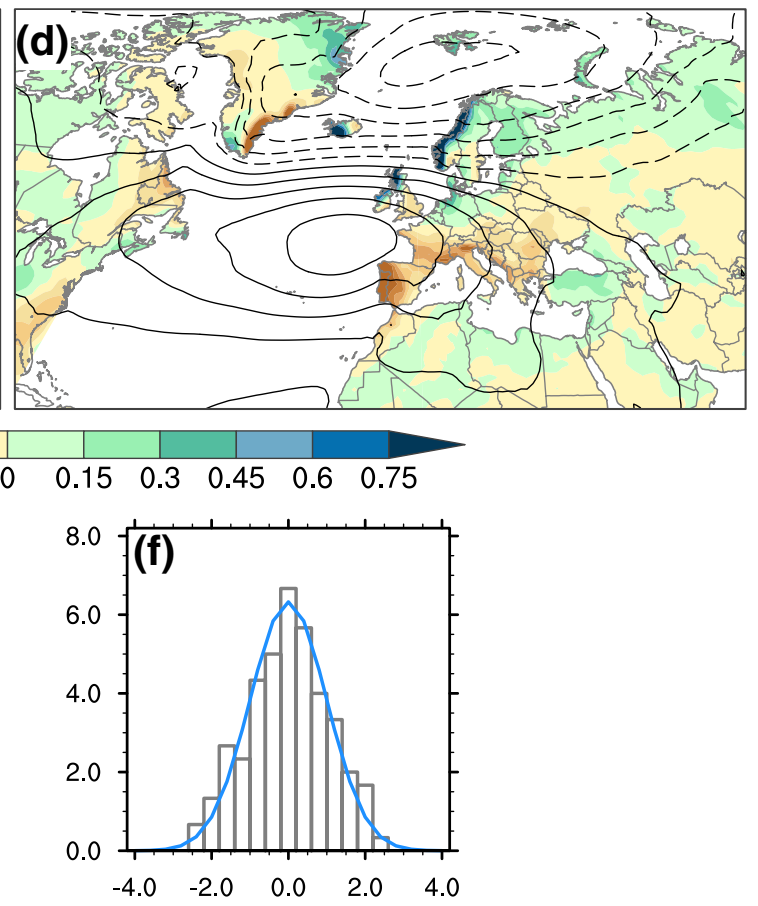

of ${ }^{\circ} \mathrm{C}$ per 30 years, precipitation in units of $\mathrm{mm}^{\text {day }}{ }^{-1}$ per 30 years, and SLP contour interval of $1 \mathrm{hPa}$ per 30 years with negative values dashed. e Histogram of the NAO trend PC (gray bars) and the expected distribution based on the interannual statistics of the NAO during 1920-2012 (blue curve); $\mathbf{f}$ as in (e) but after smoothing the trend histogram with a 3-point boxcar filter. See text for details

fact that the 40-year (2016-2055) and 50-year (2016-2065) SLP trend regressions do not differ significantly from their scaled-interannual counterparts suggests that there may be an additional source of multi-decadal variability that is influencing the statistics of simulated NAO trends over the next 30 years. One candidate is the ocean's Atlantic Meridional Overturning Circulation (AMOC), which shows an approximate 60-year periodicity in the majority of CESMLE ensemble members in both the historical (1920-2012) and future (2012-2100) segments of the simulations, 
accompanied by a weak influence on the NAO and sea ice concentrations in the Barents and Kara Seas (not shown, but see related results in Yeager et al. 2015; Delworth and Zeng 2016). The latter may explain the differences in SAT amplitudes over western Russia between the scaledinterannual and future 30-year trend regressions, as sea ice amounts are known to influence terrestrial SATs adjacent to the Arctic Ocean (i.e., Sun et al. 2015; Deser et al. 2016). Further investigation of these issues is clearly warranted but is beyond the scope of the present study. Additional information on the frequency-dependent interplay between AMOC and the NAO is provided in the idealized modeling study of Delworth and Zeng (2016).

As a last metric of the degree to which the scaling argument of Thompson et al. (2015) applies to the NAO in the CESM-LE, we compare the histogram of the 40 NAO trend (2016-2045) PC values with that of a Gaussian time series whose $\sigma$ is computed from the interannual statistics of the detrended NAO during 1920-2012, multiplied by 1.27 (Fig. 7e). Here, $\sigma$ is computed for each ensemble member individually and then averaged over all 40 members, but nearly identical results are obtained by appending the detrended NAO time series from all 40 ensemble members into one long record and then computing $\sigma$ (not shown). The trend and scaled-interannual NAO pdfs show remarkable agreement, especially when the noisy NAO trend histogram (which is based on only 40 values) is smoothed slightly with a 3-point boxcar filter (Fig. 7f). This agreement lends additional support to the applicability of the Thompson et al. (2015) scaling argument to the CESM's NAO.

In summary, our results show that in the CESM-LE, the range of uncertainty in projected NAO trends and associated influences on SAT and P over the next 30 years can be obtained to a large degree from the Gaussian statistics of NAO variability during the historical period, with some regional exceptions possibly associated with AMOC variability.

\subsubsection{Application to observations}

Next, we use the observed characteristics of presentday interannual NAO variability to estimate the error on future NAO SLP trends and associated SAT and P trends. Here, it must be borne in mind that the 93-year sample (1920-2012) of SLP observations may not be adequate for precisely estimating the statistics of the NAO, given the member-to-member variability in the statistics derived from the CESM-LE (recall Fig. 3). For this calculation, we scale the observed interannual SLP, SAT and P regression values by the factor 1.53 appropriate for a 30 -year trend and an observed NAO autocorrelation of 0.17 based on detrended data during 1920-2012 (Fig. S5b). Then we add/subtract this scaled interannual regression map to/from the anthropogenically-forced component of the trend over the next 30 years, the latter estimated from the ensemblemean of the CESM-LE (Fig. 8) or the ensemble-mean of the 38 CMIP5 models (Fig. 9). These NAO "book-ends" provide an estimate of the 5-95\% range of uncertainty in projected trends due to internal variability of the NAO based on observations superimposed upon model estimates of human-induced climate change.

It is clear from Figs. 8 and 9 that there is a broad range of uncertainty on NAO-related SLP trends over the next 30 years due to sampling fluctuations derived from the statistics of the observed NAO, with both positive and negative NAO trends possible. This indicates that internal variability will dominate over the forced response for NAO trends over the next 30 years, regardless of whether the forced response is estimated from the ensemble-mean of the CESM-LE or the CMIP5 models. Further, this range of uncertainty on the NAO-related SLP trends has substantial consequences for both SAT and P trends. In particular, P trends in northern Europe (Scandinavia and Scotland) and in countries bordering the Mediterranean Sea can change sign, while SAT trends over northern Europe and Russia can range from near zero or even slight cooling to over $4{ }^{\circ} \mathrm{C}$, depending on the polarity of the $2 \sigma \mathrm{NAO}$ trend. The similarity of these observationally-based "NAO book-end" trend maps with those derived directly from the leading EOF of the set of 40 CESM-LE SLP trend maps (Fig. 2) attests to the robustness of the results, the utility of the method of Thompson et al. (2015) to estimate uncertainty in trends from the statistics of a Gaussian time series, and the fidelity of CESM's simulation of the NAO.

We have applied the same procedure to estimate the $5-95 \%$ range of uncertainty on trends over the next 50 years (2016-2065). The results indicate that the sign of NAO-related SLP trends remains uncertain over the next 50 years (Figs. S10 and S11). However, the opposing circulation trends have a smaller impact on the range of SAT and $\mathrm{P}$ trends due to the fact that the radiatively-forced response is greater over the longer (50-year) time horizon. Thus, over the next 50 years, SAT is expected to warm everywhere, and $\mathrm{P}$ is expected to increase over most of northern Europe, western Russia and eastern North America, regardless of the polarity of the NAO trend (Figs. S10 and S11). However, the magnitude of the warming and the sign of the $\mathrm{P}$ trends over southern Europe still depend on the sign of the NAO trend over the next 50 years.

\subsection{Chance of a positive SAT or $P$ trend in the CESM-LE}

We conclude by summarizing the impact of internal variability on future climate trends by showing maps of the 


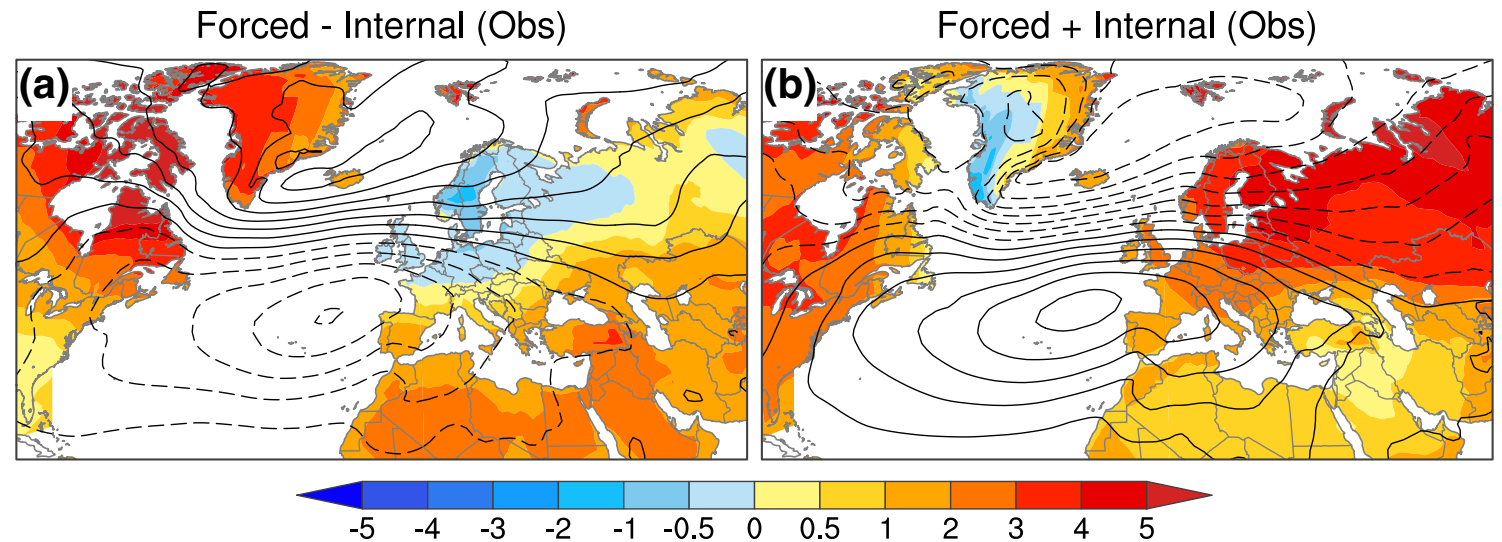

Forced - Internal (Obs)

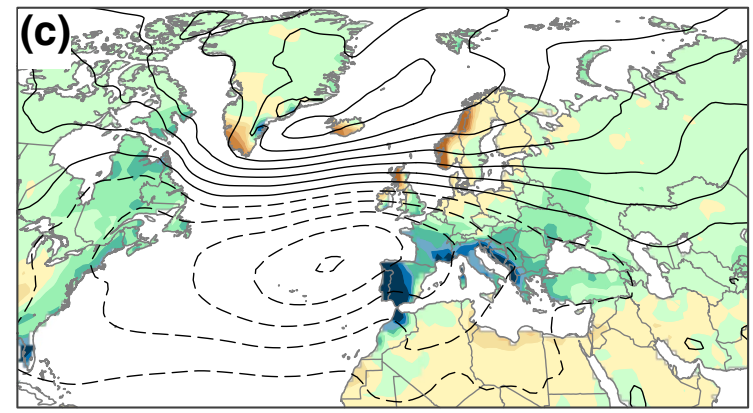

Forced + Internal (Obs)

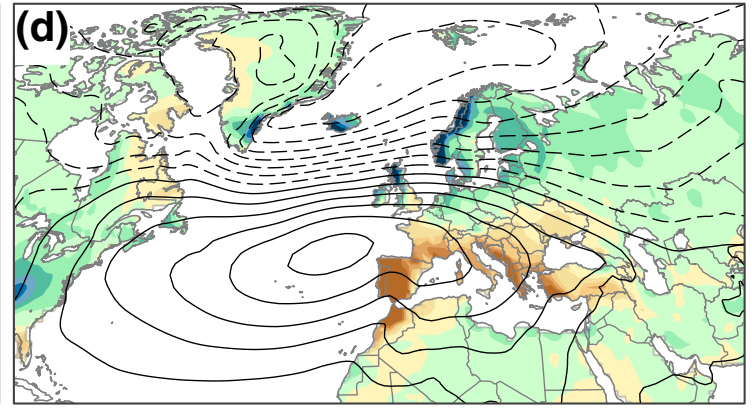

$\begin{array}{lllllllllll}-0.75 & -0.6 & -0.45 & -0.3 & -0.15 & 0 & 0.15 & 0.3 & 0.45 & 0.6 & 0.75\end{array}$

Fig. 8 Impact of the NAO on future 30-year climate trends (20162045) based on interannual statistics of the NAO from observations and the forced response from the CESM1 Large Ensemble. a, b show the expected range of future SLP and SAT trends; c, d show

chance of a positive trend in SAT and $\mathrm{P}$ over the next 30 years (Fig. 10a, b, respectively) and the next 50 years (Fig. 10c, d, respectively) according to CESM1. These probabilities are obtained by dividing the number of CESM-LE ensemble members that show a positive trend by the total number of ensemble members (40) at each location. Similar maps were shown in Deser et al. (2014) for North America, based on the CCSM3 40-member ensemble for trends over approximately the next 50 years. Note that this calculation incorporates all sources of internal variability, not just that due to the NAO.

Winter SAT is virtually guaranteed to warm over the next 30 years (e.g., chance of a positive trend exceeds 95\%) everywhere except Greenland, northern Europe and Russia where the risk is slightly lower (75-95\%; Fig. 10a). The near future is less conclusive with regard to winter $\mathrm{P}$, with many locations including southern and central Europe, Iran, and Kazakhstan showing nearly even chances for increased or decreased $\mathrm{P}$ over the next 30 years, and most regions showing values between 35 the expected range of future SLP and precipitation trends. See text for details. SLP contour interval is $1 \mathrm{hPa}$ per 30 years with negative values dashed; SAT (color shading) in units of ${ }^{\circ} \mathrm{C}$ per 30 years; and precipitation (color shading) in units of $\mathrm{mm} \mathrm{day}^{-1}$ per 30 years

and $65 \%$ (Fig. 10b). The most definitive 30-year P trends occur along the northern Russian border and adjacent to Hudson's Bay ( $>75 \%$ change of a wetter future), likely in response to diminished sea ice cover and resulting increase in atmospheric moisture, and in some areas of northern Africa and the Middle East $(<35 \%$ chance of wetting, equivalent to $>65 \%$ chance of drying; Fig. $8 b$ ). More robust trends are indicated for the next 50 years, with all locations showing $>95 \%$ chance of warming (Fig. 10c) and a $>85 \%$ chance of increasing P over northern Europe and western Russia as well as most of eastern North America, and a $>85 \%$ chance of drying over northwestern Africa and regions directly adjacent to the Mediterranean Sea (Fig. 10d). Note that the sign of precipitation trends in areas most directly impacted by the NAO such as southern Europe and the west coasts of Norway, the U.K. and Iceland, remains uncertain even for the next 50 years (Fig. 10d) consistent with the results shown in Figs. S10 and S11. 
Forced (CMIP5) - Internal (Obs)

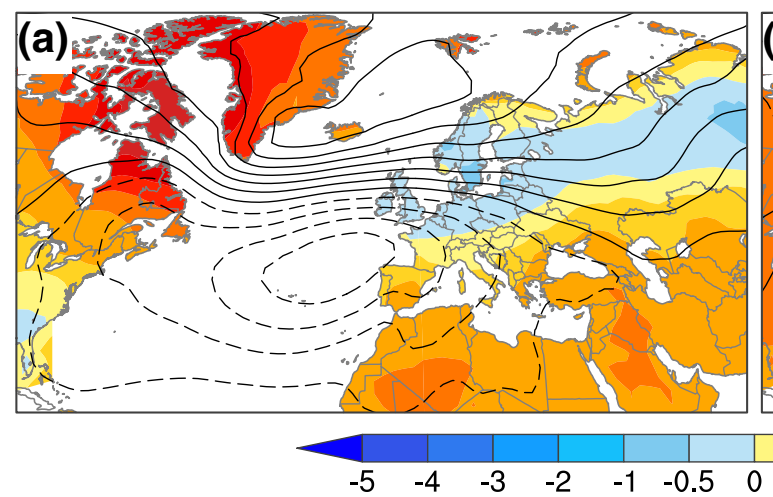

Forced (CMIP5) - Internal (Obs)

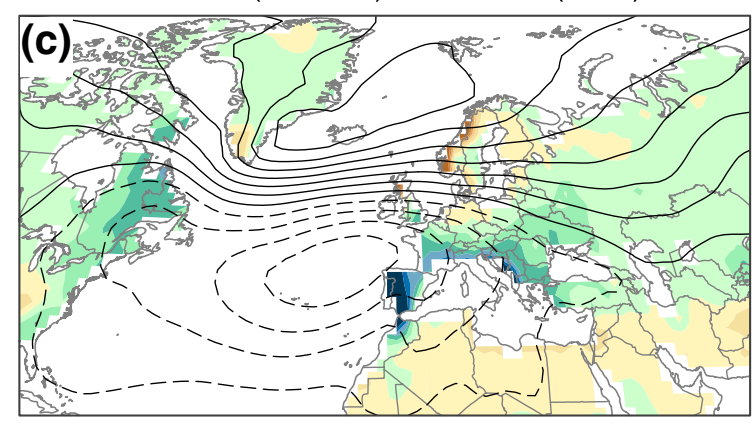

Forced (CMIP5) + Internal (Obs)

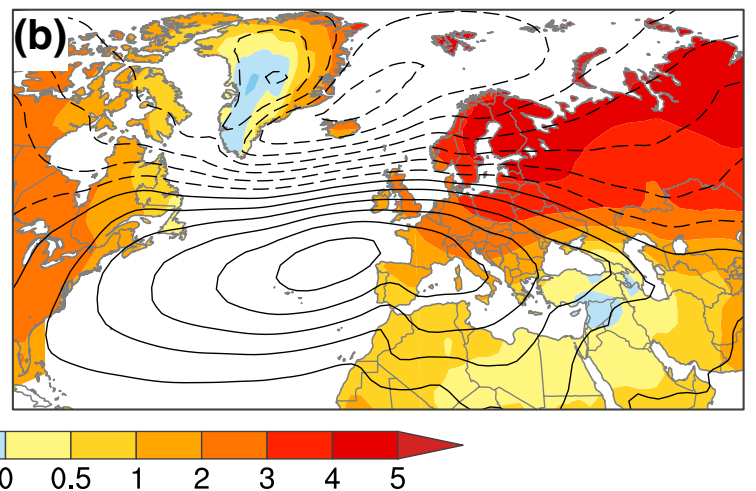

Forced (CMIP5) + Internal (Obs)

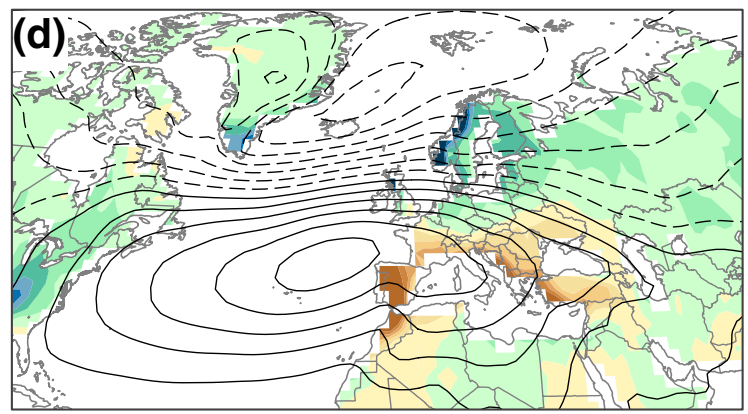

$\begin{array}{lllll}0.15 & 0.3 & 0.45 & 0.6 & 0.75\end{array}$

Fig. 9 As in Fig. 8 but using the CMIP5 multi-model mean in place of the CESM1 Large Ensemble for the forced trend

\section{Summary and discussion}

This study has highlighted the role of internal variability of the NAO, the leading mode of atmospheric circulation variability over the Atlantic/European sector, on winter (December-March) surface air temperature (SAT) and precipitation $(\mathrm{P})$ trends over the next 30 years (and the next 50 years: see Supplemental Materials) using a new 40-member ensemble of climate change simulations with CESM1. Each member is subject to the identical increase in GHG, but starts from a slightly different initial atmospheric state in 1920. Thus, any spread in trends across the ensemble is a measure of the relative importance of unpredictable natural variability and forced climate change.

Because the NAO is primarily controlled by intrinsic atmospheric dynamics, it constitutes a major source of unpredictable natural variability whose impacts will be superimposed upon those of anthropogenic climate change. Thus, future climate trends in regions affected by the NAO are best conveyed in terms of an expected range that incorporates both the natural variability and the forced climate change signal. Our results show that this expected range resulting from internal variability of the NAO is substantial for both SAT and P trends over the next 30 years, and in the case of $\mathrm{P}$ can even change the sign of the trend. While the NAO's impacts on SAT and P trends over the next 50 years are smaller, they remain important for assessing the magnitude of future warming and precipitation change. Further, the large-scale imprint of the NAO on surface climate imparts spatial coherence to this leading source of uncertainty in future climate trends, with implications for agricultural and water resources. Although the NAO is the dominant pattern of atmospheric circulation variability, accounting for about half of the total winter SLP variance on both interannual and multi-decadal time scales, other large-scale structures of internal circulation variability will also undoubtedly contribute to uncertainty in future climate trends.

While the statistics of 30-year (or longer) NAO trends and associated surface climate impacts cannot be reliably determined from the short observational record, we have made use of a simple relationship between the statistics of trends of any length and the statistics of the interannual variability, provided the time series is Gaussian (Thompson et al. 2015). This relationship, which we show holds to a large extent in the CESM-LE and in the long CESM coupled and atmospheric control simulations, has enabled us to use the observed interannual NAO statistics to infer 


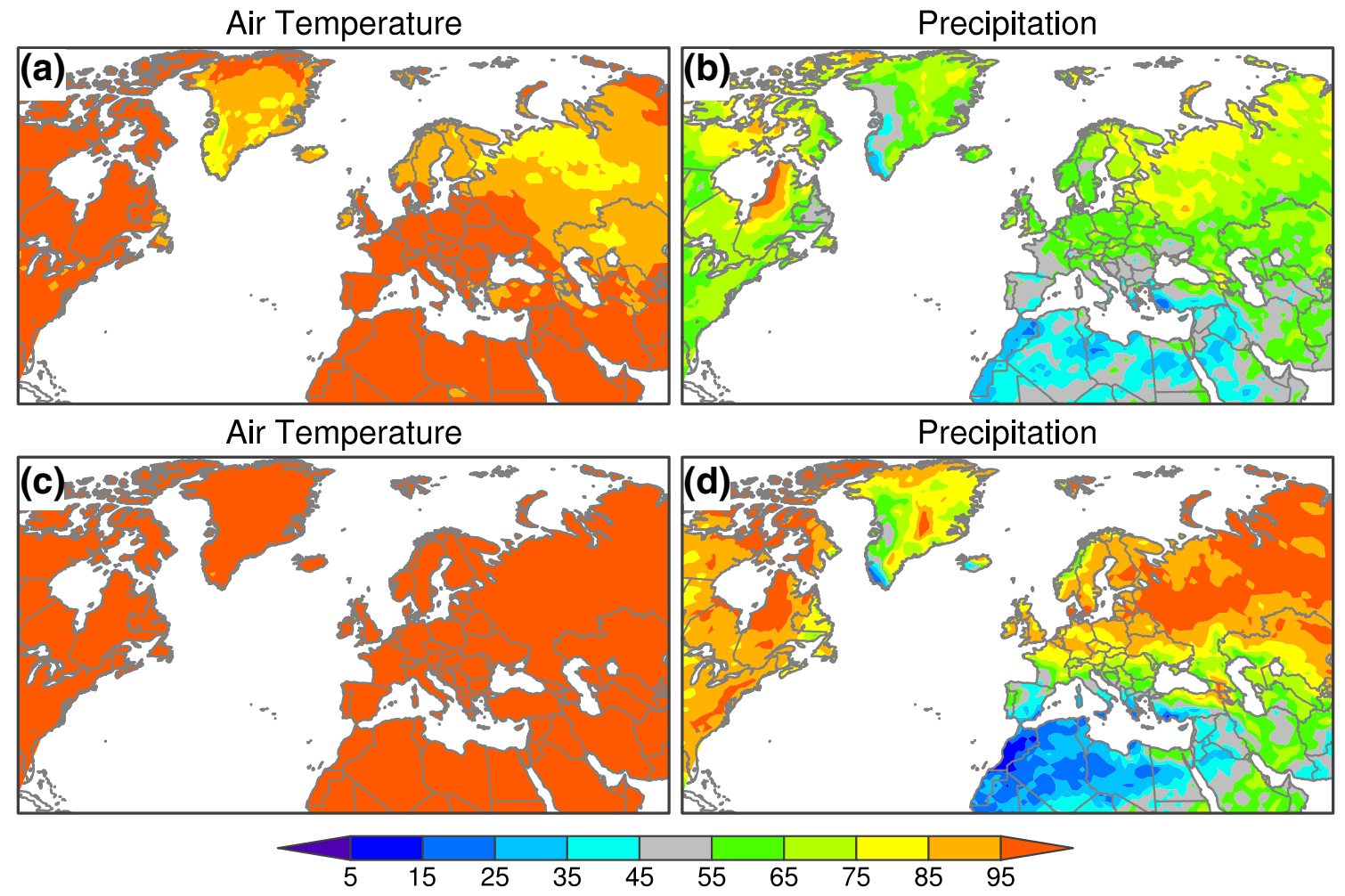

Fig. 10 Percent chance of a positive 30-year trend (2016-2045) in winter (a) SAT and (b) precipitation from the CESM1 Large Ensemble. c As in (a) but for a 50-year trend (2016-2065); d as in (b) but

the magnitude of 30-year (and 50-year) NAO trends that will be superimposed upon anthropogenic climate change. We find that the expected $95 \%$ range of future climate trends induced by NAO fluctuations estimated from the observed statistics of the NAO and the modeled response to increased GHGs is largely similar to that obtained from the CESM-LE directly, attesting to the fidelity of the model's representation of the NAO and the utility of this approach. We note further that even with nearly 100 years of data, the interannual statistics of the NAO are subject to considerable uncertainty, including its standard deviation and autocorrelation, with consequences for impacts on SAT and P. Thus, one might argue that a large ensemble of climate change simulations with a given model still provides useful guidance to the range of future climate trends expected from the superposition of natural variability and forced climate change.

Acknowledgements We thank the Reviewers for their thoughtful comments and suggestions. We also appreciate discussions with Drs. Isla Simpson and Elizabeth Barnes during the course of this work. We acknowledge all the contributors to the CESM Large Ensemble Community Project (http://www.cesm.ucar.edu/projects/communityprojects/LENS/) and supercomputing resources for the Large Ensemble provided by NSF/CISL/Yellowstone. NCAR is sponsored by the National Science Foundation. for a 50-year trend (2016-2065). Note that for precipitation, a small chance of a positive trend (moistening) is equivalent to a high chance of a negative trend (drying). Color bar is in units of $\%$

Open Access This article is distributed under the terms of the Creative Commons Attribution 4.0 International License (http:// creativecommons.org/licenses/by/4.0/), which permits unrestricted use, distribution, and reproduction in any medium, provided you give appropriate credit to the original author(s) and the source, provide a link to the Creative Commons license, and indicate if changes were made.

\section{References}

Barnes EA, Polvani LM (2015) CMIP5 projections of Arctic amplification, of the North American/North Atlantic circulation, and of their relationship. J Climate 28:5254-5271

Becher A, Finger P, Meyer-Christoffer A, Rudolf B, Schamm K, Schneider U, Ziese M (2013) A description of the global landsurface precipitation data products of the Global Pre- cipitation Climatology Centre with sampling applications in- cluding centennial trend analysis from 1901-present. Earth Syst Sci Data 5:71-99

Bracco A, Kucharski F, Kallummal R, Molteni F (2004) Internal variability, external forcing and climate trends in multi-decadal AGCM ensembles. Clim Dyn 23:659-678

Branstator G, Selten F (2009) "Modes of variability" and climate change. J Clim 22(10):2639

Compo GP et al (2011) The twentieth century reanalysis project. Quart J Roy Meteor Soc 137:1-28

Cook ER (2003) Multi-proxy reconstructions of the north atlantic oscillation (NAO) index: a critical review and a new well-verified winter NAO index reconstruction back to AD 1400. In: 
Hurrell JW, Kushnir Y, Ottersen G, Visbeck M (eds) The north atlantic oscillation: climatic significance and environmental impact. American Geophysical Union, Washington, D. C

Delworth T, Zeng F (2016) The impact of the north atlantic oscillation on climate through its influence on the atlantic meridional overturning circulation. J Clim 29:941-962

Deser C, Phillips AS (2009) Atmospheric circulation trends, 1950 2000: the relative roles of sea surface temperature forcing and direct atmospheric radiative forcing. J Clim 22:396-413. doi:10. 1175/2008JCLI2453.1

Deser C, Alexander MA, Xie S-P, Phillips AS (2010) Sea surface temperature variability: patterns and mechanisms. Ann Rev Mar Sci 2:115-143

Deser C, Phillips AS, Bourdette V, Teng H (2012) Uncertainty in climate change projections: the role of internal variability. Clim Dyn 38:527-546. doi:10.1007/s00382-010-0977-x

Deser C, Phillips AS, Alexander MA, Smoliak BV (2014) Projecting north american climate over the next 50 years: uncertainty due to internal variability. J Clim 27:2271-2296

Deser C, Sun L, Tomas RA, Screen J (2016) Does ocean coupling matter for the northern extratropical response to projected Arctic sea ice loss? Geophys Res Lett 43(5):2149-2157. doi:10.1002/2 016GL067792

Dunstone N, Smith D, Scaife A, Hermanson L, Eade R, Robinson N, Andrews M, Knight J (2016) Skilful predictions of the winter North Atlantic Oscillation one year ahead. Nat Geosci 9:809-814

Feldstein SB (2000) The timescale, power spectra, and climate noise properties of teleconnection patterns. J Climate 13:4430-4440

Hansen J, Ruedy R, Sato M, Lo K (2010) Global surface temperature change. Rev Geophys 48:RG4004

Hoerling MP, Hurrell JW, Xu T (2001) Tropical origins for recent North Atlantic climate change. Science 292:90-92

Hoerling MP, Hurrell JW, Xu T, Bates GT, Phillips AS (2004) Twentieth century north atlantic climate change. Part II. understanding the effect of indian ocean warming. Clim Dyn 23:391-405

Hurrell JW (1995) Decadal trends in the North Atlantic Oscillation: Regional temperatures and precipitation. Science 269:676-679

Hurrell JW (1996) Influence of variations in extratropical wintertime teleconnections on Northern Hemisphere temperature. Geophys Res Lett 23:665-668

Hurrell JW, Deser C (2009) North Atlantic climate variability: the role of the north atlantic oscillation. J Mar Syst 78:28-41

Hurrell JW, Kushnir Y, Ottersen G, Visbeck M (eds) (2003) The north atlantic oscillation: climate significance and environmental Impact, Geophys. Monogr. Ser, vol. 134. AGU, Washington, D. $\mathrm{C}$

Hurrell JW, Hoerling MP, Phillips A, Xu T (2004) Twentieth century north atlantic climate change. Part I: assessing determinism. Clim Dyn 23:371-389

Hurrell JW et al (2013) The community earth system model. Bull Am Met Soc 94:1339-1360

Kay JE, Deser C, Phillips A, Mai A, Hannay C, Strand G, Arblaster J, Bates S, Danabasoglu G, Edwards J, Holland M, Kushner P,
Lamarque J-F, Lawrence D, Lindsay K, Middleton A, Munoz E, Neale R, Oleson K, Polvani L, Vertenstein M (2015) The community earth system model (CESM) large ensemble project: a community resource for studying climate change in the presence of internal climate variability. Bull Amer Met Soc 96:1333-1349

Kidston J et al (2015) Stratospheric influence on tropospheric jet streams, storm tracks and surface weather. Nat Geosci 8:433-440

Osborn TJ, Jones PD (2014) The CRUTEM4 land-surface air temperature data set: construction, previous versions and dissemination via Google earth. Earth Syst Sci Data 6:61-68

Ottersen G, Benjamin P, Beldgrano A, Stenseth NC (2001) Ecological effects of the north atlantic oscillation. Oecologia 128:1-14

Scaife AA et al (2014) Skillful long-range prediction of European and North American winters. Geophys Res Lett 41:2514-2519

Selten FM, Branstator GW, Dijkstra HA, Kliphuis M (2004) Tropical origins for recent and future Northern Hemisphere climate change. Geophys Res Lett 31:L21205

Stenseth NC, Ottersen G, Hurrell JW, Mysterud A, Lima M, Chan K-S, Yoccoz NG, Ådlandsvik B (2003) Studying climate effects on ecology through the use of climate indices, the North Atlantic Oscillation, El Niño southern oscillation and beyond. Proc R Soc Lond B Biol Sci 270:2087-2096

Sun L, Deser C, Tomas RA (2015) Mechanisms of stratospheric and tropospheric circulation response to projected Arctic sea ice loss. J Clim 28:7824-7845

Taylor KE, Stouffer RJ, Meehl GA (2012) An Overview of CMIP5 and the experiment design. Bull Amer Meteorol Soc 93(4):485-498

Thompson DWJ, Wallace JM, Hegerl GC (2000) Annular modes in the extratropical circulation. Part II: Trends". J Clim 13:1018-1036

Thompson DWJ, Barnes EA, Deser C, Foust WE, Phillips AS (2015) Quantifying the role of internal climate variability in future climate trends. J Climate 28:6443-6456

Ulbrich U, Christoph M (1999) A shift of the NAO and increasing storm track activity over Europe due to anthropogenic greenhouse gas forcing. Clim Dyn 15:551-559

Visbeck M, Chassignet EP, Curry RG, Delworth TL, Dickson RR, Krahmann G (2003) The Ocean's Response to North Atlantic Oscillation Variability. In: Hurrell JW, Kushnir Y, Ottersen G, Visbeck M (eds) The North Atlantic Oscillation: Climatic Significance and Environmental Impact. American Geophysical Union, Washington, D. C

Vose RS et al (2012) NOAA's Merged Land-Ocean Surface Temperature Analysis. Bull Amer Meteor Soc 93:1677-1685

Wunsch C (1999) The interpretation of short climate records, with comments on the North Atlantic and Southern Oscillations. Bull Amer Meteor Soc 80:245-255

Yeager S, Karspeck A, Danabasoglu G (2015) Predicted slowdown in the rate of Atlantic sea ice loss. Geophys Res Lett $42: 10,704-10,713$ 